Original Research

\title{
Effects of Jejunal Manipulation During Surgical Laparotomy Techniques and Its Evaluation Using Physical, Clinical, and Echographic Parameters in Horses
}

\author{
Adriana Yolanda Díaz-Archundia ${ }^{a}$, José Antonio Ibancovichi-Camarillo ${ }^{\mathrm{b}}$, \\ Sergio Recillas-Morales ${ }^{\mathrm{b}}$, Arturo Venebra-Muñoz ${ }^{\mathrm{c}}$, Moisés Cipriano-Salazar ${ }^{\mathrm{d}}$, \\ Alejandro Cordova-Izquierdo ${ }^{\mathrm{e}}$, Pedro Sánchez-Aparicio ${ }^{\mathrm{b}, *}$ \\ ${ }^{a}$ Hospital Veterinario Grandes Especies, Faculty of Veterinary Medicine, Universidad Autónoma del Estado de México, Toluca, México \\ ${ }^{\mathrm{b}}$ Department of Pharmacology, Anesthesia and Analgesia, Faculty of Veterinary Medicine, Universidad Autónoma del Estado de México, Toluca, México \\ ' Sciences School, Universidad Autónoma del Estado de México, Toluca, México \\ ${ }^{\mathrm{d}}$ Unidad Académica de Medicina Veterinaria y Zootecnia, Universidad Autónoma de Guerrero, Altamirano, México \\ e Departament of Agricultural and Animal Production, Universidad Autónoma Metropolitana, Unidad Xochimilco, CDMX, México
}

\section{A R T I C L E I N F O}

\section{Article history:}

Received 6 July 2017

Received in revised form 10 August 2017

Accepted 14 August 2017

Available online 19 August 2017

\section{Keywords:}

Laparotomy

Enterotomy

Enterectomy

Equine

Echography

Jejunum

\begin{abstract}
A B S T R A C T
The laparotomy surgical procedure allows for the identification and correction of intestinal lesions associated with acute abdomen in horses. The clinician relies on various laparotomy techniques to diagnose and treat this syndrome, and to date, the postsurgical effects of these techniques have not been clarified. The aim of this study was to evaluate the effects of jejunal manipulation during three laparotomy techniques through physical and clinical parameters and echography. Fifteen healthy horses were randomly assigned to three groups: animals in $\mathrm{G}_{1}(\mathrm{n}=5)$ were subjected to an exploratory laparotomy, animals in $\mathrm{G}_{2}(\mathrm{n}=5)$ to a laparotomy with an enterotomy, and animals in $G_{3}(n=5)$ to a laparotomy with an enterectomy. Degree of pain, jejunal wall thickness, and clinical parameters were evaluated before and after surgery. Horses in $\mathrm{G}_{3}$ had higher heart rates, respiratory frequency, degree of pain, and jejunal wall thickness compared with $\mathrm{G}_{1}$. Clinical variables during the postsurgical period were compared among the laparotomy techniques, and higher values of erythrocytes, leucocytes, neutrophils, and proteins were found in horses belonging to $G_{3}$ compared to those in $G_{1}$. Intestinal manipulation during the surgical procedure altered the physical and clinical parameters, as well as the results of the echography evaluation, with more significant effects from laparotomy with enterectomy. In the postsurgical period, the heart rate of horses in $\mathrm{G}_{3}$ was higher $(P=.02)$ than the values obtained in $G_{1}$ and $G_{2}$. Upon the evaluation of degree of pain, statistically significant differences $(P=.04)$ were identified between horses in $G_{1}$ versus $\mathrm{G}_{3} \mathrm{G}_{3}$ animals presented a higher degree of pain. Regarding the erythrocytes $(\mathrm{L} / \mathrm{L})$, higher values were measured in $\mathrm{G}_{3}(P=.001)$ in comparison with $\mathrm{G}_{1}$ and $\mathrm{G}_{2}$. These results suggest that meticulous tissue handling is essential to minimize intestinal trauma and inflammation.
\end{abstract}

(c) 2017 Elsevier Inc. All rights reserved.

\footnotetext{
Animal welfare/ethical statement: All methods and procedures used in this study were in compliance with the guidelines of the Mexican law "Official Mexican Standard \# 062-ZOO-1999 of the technical specifications for production, care and use of laboratory animals". On the protection of animals used for scientific purposes, and were approved by the Animal Ethics Committee for the Care and Use and Animals of university of Autonomous of State Mexico, México.
}

Conflict of interest statement: The authors declare that they don't have any conflict of interest.

* Corresponding author at: Pedro Sánchez-Aparicio, El Cerrillo Piedras Blancas, Toluca, Estado de México, México C.P. 50090.

E-mail address: pedrosanchezaparicio0@gmail.com (P. SánchezAparicio). 


\section{Introduction}

Acute abdomen is a term for a group of signs indicative of abdominal pain originating with the digestive system or other abdominal organ [1], which can be caused by intestinal obstruction and block of food passage through the intestines. Acute abdomen has an approximate clinical incidence of 3.5-10.5 cases per 100 horses per year [2]; between $7 \%$ and $10 \%$ of the acute abdomen cases require immediate surgical treatment [3]. Acute abdomen can be diagnosed and treated with a laparotomy surgery, which is performed to localize, identify, and correct the intestinal lesion [4]. Surgical laparotomy techniques performed in horses with signology of acute abdominal syndrome may include at the discretion of the surgeon, manipulation of the jejunum or other tubular organs to perform the correction, other techniques of laparotomy as a surgical approach, and hand-assisted laparoscopic correction exist [5]. The degree of pain and thickness of the intestinal wall at jejunum level varies according to the technique used [6]. To date, there are no studies in horses with or without sinology of acute abdominal syndrome that indicates the degree of pain caused by the jejunal manipulation or the increase in the thickness of the intestinal wall based on physical and ultrasound techniques. It is therefore necessary to carry out evaluations of the effect of manipulation on horses without acute abdominal syndrome, in order to identify the effect of manipulation.

Laparotomy techniques commonly used by the clinician are exploratory laparotomy, laparotomy with enterotomy, and laparotomy with enterectomy [7]. Hopster-Iversen et al [8] suggested that inflammation of the small intestine or intestinal manipulation can result in disease. Currently, the postoperative effects including inflammation and degree of pain generated by surgical manipulation of the jejunum during each of the surgical procedures mentioned above have not been evaluated. The objective of this study was to evaluate the effects of jejunal manipulation in the three surgical techniques using physical, clinical, and echographic parameters in horses without acute abdomen.

\section{Materials and Methods}

\subsection{Animals and Experimental Treatments}

The study included 15 male, intact or castrated, mixed breed horses with an average age of 10.5 years and average weight of $183.5 \mathrm{~kg}$. The bioethics and animal welfare commission of the FMVZ-UAEMex approved the investigation. The horses were transported to the Large Species Hospital of the UAEMex, according to the eighth section of the Official Mexican Norm NOM-024-ZOO-1995 [9], animal health specifications and features for the transport of animals, their products and by-products, chemical, pharmaceutical, biological, and food products for animal use or consumption. The animals were under observation during the 7 days before surgery, to allow them to adapt to their environment and guarantee that they were clinically healthy through physical and clinical examination, and abdominal echography.
The horses were randomly assigned to three groups using a random numbers table. Animals in $\mathrm{G}_{1}(\mathrm{n}=5)$ underwent an exploratory laparotomy, animals in $\mathrm{G}_{2}(\mathrm{n}=5)$ underwent a laparotomy with an enterotomy, and animals in $\mathrm{G}_{3}(\mathrm{n}=5)$ underwent a laparotomy with an enterectomy.

\subsection{Physical Evaluation}

The physical evaluation consisted of the evaluation of the heart and respiratory rate, and degree of pain as described by Mair [10]. During the 24-hour period before surgery, four evaluations were performed at 6-hour intervals and the results were considered normal. The start of surgery was considered hour zero. The critical postsurgery period consisted of 3 days, and 12 physical evaluations at 6 -hour intervals were performed during this period. Data were grouped by intervals of 24,48 , and 72 hours postsurgery. The values of these variables were expressed as mean \pm standard error of the mean.

\subsection{Echographic Evaluation}

Four echography evaluations were performed per horse using digital ultrasonography equipment MindRay Dp2200 vet (Medical International Limited, Nansham, Shenzhen, Chine), which included a convex transducer with multifrequency of 2.5-5 $\mathrm{MHz}$. One evaluation per horse per day was performed at approximately the same time of day. The first evaluation was performed 24 hours presurgery and the other three at 24, 48, and 72 hours after surgery. Measurement of large intestinal thickness was performed using the FLASH system standardized by Busoni et al [11].

First, the left flank was clipped using a hair clipper with a \# 14 blade (Andis Company, Sturtevant). Then, the ventral area of the left flank was sprayed with $96 \%$ ethylic alcohol to locate the jejunum with the transducer. During the echography study, one image was captured for each horse and evaluated based on the standards described by Beccati et al [12] for a normal jejunum.

\subsection{Hematologic Evaluation}

Blood samples were collected from each horse 24 hours before the surgical procedure and at 24, 48, and 72 hours postsurgery. A sterile graduated $10 \mathrm{~mL}$ syringe and a $21 \mathrm{G} \times$ $32 \mathrm{~mm}$ needle (BD, Plastipack, México) and a sterile vacutainer tube with EDTA (Monoject TM 15\% EDTA, México) were used to obtain $5 \mathrm{~mL}$ of blood from the jugular vein. The blood samples were sent immediately to the Centro de Investigación y Estudios Avanzados en Salud Animal of the FMVZ-UAEMex, to obtain a complete blood count, which included measurement of the hematocrit, hemoglobin, erythrocytes, leucocytes, neutrophils, lymphocytes, eosinophils, and plasma proteins.

\subsection{Surgical Procedure}

\subsubsection{Presurgical Preparation}

The horses were fasted for 12 hours prior to surgery, although they did have access to water ad libitum. A sterile Teflon IV catheter of $14 \mathrm{G} \times 2^{\prime \prime}$ caliber (Punzocat, Equipos 
Médicos Vizcarra, México) was placed in the jugular vein. Pain management consisted of a nonsteroidal anti-inflammatory drug, flunixin meglumine (Napzin $50 \mathrm{mg} / \mathrm{mL}$ ), administered intravenously (IV) at a dose of $1.1 \mathrm{mg} / \mathrm{kg}$. Antibiotic therapy consisted of sodium penicillin (Pisacilina 5,000.000) at $22.0 \mathrm{mg} / \mathrm{kg}$ IV and gentamicin (Gertaerba $100 \mathrm{mg} / \mathrm{mL}$ ) at $6.6 \mathrm{mg} / \mathrm{kg}$ IV. Before entering the operating room, the mouth and hooves were cleaned and the abdomen was clipped over the lineal band to improve sterility of the procedure and fixation of the adhesive, impermeable surgical drapes.

\subsubsection{Anesthesia}

Preanesthetic medication consisted of xylazine (ProcinEquus $10 \%$ ) at $1.1 \mathrm{mg} / \mathrm{kg}$ IV. Once the sedation plane was reached, induction was performed using diazepam (Valium $10 \mathrm{mg} / 2 \mathrm{~mL}$ ) at $0.1 \mathrm{mg} / \mathrm{kg}$ IV and ketamine (Anesket $1000 \mathrm{mg} / 10 \mathrm{~mL}$ ) at $2.2 \mathrm{mg} / \mathrm{kg}$ IV. Finally, an orotracheal tube was placed and connected to a rebreathing tube, and the anesthetic plane was maintained with isofluorane vaporized in $100 \%$ oxygen.

\subsection{Surgical Procedure}

\subsubsection{Exploratory Laparotomy Technique}

The technique described by Ducharme [7] was adapted to the conditions of this study. The approach started with positioning the horse in dorsal recumbency position followed by laparotomy through the ventral midline, starting with a $10 \mathrm{~cm}$ skin incision from caudal to cranial using a no. 22 scalpel (Braund, México). Hemorrhage of the incised skin was controlled, and a $2.5 \mathrm{~cm}$ incision was made in the line alba starting at the umbilicus and going cranially. The surgeon bluntly dissected through the peritoneum and then proceeded to an abdominal exploration of the four quadrants with the viscera in situ. Exteriorization of the viscera started at the apex of the cecum, and the apex was moved caudally to expose the dorsal and lateral cecal bands. The ileocecal fold was located to identify the ileum based on its thicker wall and the antimesenteric insertion of the ileocecal fold. The small intestine was exteriorized and explored once the rostral part of the duodenum was reached. The cecocolic fold was located to exteriorize the colon at the level of the pelvic flexure. Finally, the surgeon introduced the colon back into the abdominal cavity starting with the pelvic flexure on the left caudal side and the apex of the cecum on the cranial side.

\subsubsection{Enterotomy Technique}

This technique began with an exploratory laparotomy technique in the same manner as for $G_{1}$ above. Once the intestines were exteriorized, the enterotomy technique was performed as described by Ducharme [7]. This technique consisted of locating the pelvic flexure on the antimesenteric band of the large intestine. The zone was isolated with impermeable surgical planes, which were sterilized using gamma radiation (Rüstung, Hindernis, Germany), and the remainder of the exposed intestines were placed back in the abdominal cavity. An incision of approximately $6 \mathrm{~cm}$ was made in the pelvic flexure through its longitudinal axis, and the contents of the colon were evacuated using a nasogastric tube (KI-400, Kalayjian Industries, Signal Hill) connected to a water hose. The incision was closed with a simple continuous suture pattern in the muscular and serous layers, which was reinforced with a Cushing pattern using an absorbable multifilament braided polyglycolic acid 2-0 suture (Surgicryl).

\subsubsection{Enterectomy Technique (Anastomosis)}

This technique began with an exploratory laparotomy; then, the intestines were exteriorized, and an anastomosis was performed as described by Ducharme [7]. The length of the small intestine resected was less than $20 \%$ of the total length of the jejunum and equal to $1.0 \mathrm{~m}$. The mesentery segment was transected starting with a line slightly distal to the first vascular pedicle. Each mesenteric vessel was ligated, and the mesentery was closed with a simple continuous suture pattern. In both cases, an absorbable multifilament braided polyglycolic acid 2-0 suture (Surgicryl PGA Atramat, Brasil) was used. The resected fragment was blocked with intestinal clamps in an oral and aboral direction, and the incision was made with a no. 22 scalpel (Braund, México). The intestinal segment was elevated dorsally to prevent the intestinal contents from falling into the abdominal cavity. Then, the anastomosis was performed starting at the mesenteric side and finishing at the antimesenteric side and joining the ends of the intestinal fragments with the same suture material. The abdominal wall, muscular layer, and skin were closed using the same procedure in all three groups. For the muscle layer, a continuous simple suture pattern with an absorbable multifilament braided polyglycolic acid 2-0 suture (Surgicryl PGA Atramat) was used. The skin was closed with a mattress suture pattern with polyamide monofilament 1 suture (Supramid, KRUUSEZ, Dinamarca). A water-resistant aerosol (VETOQUINOL, Francia) bandage (Aluspray) was administered, and sterile gauze dressing was placed on the incision and secured with simple stitches.

\subsubsection{Postsurgical Procedure}

The horses stayed for 3 days in the intensive care unit of the hospital. Postsurgery pain management was based on the protocol described by Sánchez and Robertson [13]. Flunixin meglumine at $1.1 \mathrm{mg} / \mathrm{kg}$ IV was administered every 12 hours. Antibiotic therapy was based on the protocol described by Dallap-Schaer et al [14] and consisted of sodium penicillin at $22.000 \mathrm{mg} / \mathrm{kg}$ IV every 6 hours for 5 days and gentamicin at $6.6 \mathrm{mg} / \mathrm{kg}$ IV every 24 hours for 5 days.

2.6.4.1. Nutritional Management. All study animals received water ad libitum and a diet based on soaked oat hay, according to the nutritional therapy proposed by Rooney [15]. The first ration postsurgery was provided at 12,24 , and 48 hours postsurgery to animals in $G_{1}, G_{2}$, and $G_{3}$, respectively. All animals received the rest of the rations at 8-hour intervals during 3 days.

\subsection{Statistical Analysis}

Data of the physical evaluation and preechography and postechography were grouped and summarized as mean \pm standard error of the mean. Data were analyzed using a one-way analysis of variance followed by a Tukey's analysis to make a comparison between groups and times. The level of significance was set at $P<.05$. Analyses were performed with the statistical software Prims Graph 5. 


\section{Results}

\subsection{Presurgical Evaluation of Physical, Clinical, and} Echographic Parameters

When comparing the laparotomy techniques mentioned above, no statistically differences were observed. There were no statistically differences in the heart rates $(P=.98)$ nor in respiratory rate $(P=.41)$. The degree of pain was zero in the three groups. Jejunal wall thickness was not different among groups $(P=.74)$.

When making a comparison between the laparotomy techniques, no statistically differences were identified in any of the variables. No differences were observed for $G_{1}$, $\mathrm{G}_{2}$, and $\mathrm{G}_{3}$ in the values registered for the complete blood count $(P=.93)$, hemoglobin $(P=.94)$, erythrocytes $(P=.4)$, leucocytes $(P=.93)$, neutrophils $(P=.79)$, and lymphocytes $(P=.98)$

\subsection{Postsurgical Evaluation of the Physical, Clinical, and Echographic Parameters}

During the 3 days of the postsurgical period, the physiologic parameters, degree of pain, and echographic jejunal wall thickness were evaluated. The heart rate of horses in $\mathrm{G}_{3}$ was higher $(P=.02)$ than the values obtained in $\mathrm{G}_{1}$ and $\mathrm{G}_{2}$. The respiratory frequencies were not different among groups $(P=.17)$. Upon the evaluation of degree of pain, statistical differences $(P=.04)$ were identified between horses in $G_{1}$ versus $G_{2}$. $G_{3}$ animals presented a higher degree of pain. A similar tendency was observed in the postsurgical echography procedure, since the jejunal wall thickness was higher in the animals in $\mathrm{G}_{3}$ in comparison with the horses in $G_{1}$ and $G_{2}(P=.01)$.

The values obtained from the hemogram were compared between techniques. Regarding the erythrocytes, higher values were measured in $\mathrm{G}_{3}(P=.001)$ in comparison with $\mathrm{G}_{1}$ and $\mathrm{G}_{2}$. Regarding the leucocytes, animals in $\mathrm{G}_{3}$ had an increased number of white blood cells, the differences of which were highly significant $(P<.001)$ when compared to $G_{1}$ and $G_{2}$. A similar tendency was observed for neutrophils of animals in $\mathrm{G}_{3}(P=.001)$, as well as in the amount of plasma proteins $(P=.002)$.

\subsection{Exploratory Laparotomy Technique: Presurgical and Postsurgical Evaluation}

Characterization of the effects of exploratory laparotomy on physiologic parameters, degree of pain, and jejunal wall thickness, as well as patient evolution during the critical period (0-72 hours postsurgery) are indicated in Table 1. Regarding the heart rate, horses evaluated in the 24 hours postsurgical period showed a statistically higher $(P<.05)$ heart rate relative to the baseline value. Regarding the assessment of the degree of postsurgical pain during the critical period, a statistically higher degree of pain was recorded $(P=.01) 24$ hours postsurgery.

The results of clinical parameters obtained during the presurgical ( -24 hours) and postsurgical (24, 48, and 72 hours) periods are included in Table 1 . The highest levels of erythrocytes were observed at 24,48 , and 72 hours postsurgery and were statistically different $(P<.05)$ from the baseline values obtained before surgery ( -24 hours). The level of leukocytes evaluated in the presurgical and postsurgical stages, and a statistically significant postsurgical increase $(P=.004)$ at 24 and 48 hours was recorded; however, it was noted that as the critical recovery period progressed, a value similar to the one obtained in the presurgical period was recorded at 72 hours postsurgery which was statistically different from the values obtained at 24 and 48 hours postsurgery. The neutrophils of the horses evaluated at 24 hours postsurgery showed a higher increase in their levels with the highest values recorded at 48 and 72 hours postsurgery $(P=.0001)$. Regarding the lymphocytes, the lowest value was obtained at 24 hours postsurgery, which was statistically different from those obtained at -24 hours presurgery and 48 and 72 hours postsurgery. With regard to the plasma proteins, the values recorded at 24 and 48 hours postsurgery showed a statistically higher increase relative to the baseline values obtained before the surgical procedure ( -24 hours).

\subsection{Laparotomy With Enterotomy Technique: Presurgical and Postsurgical Evaluation}

Regarding the heart rate, there was a statistically higher increase $(P=.01)$ at 24 hours postsurgery compared with the presurgical ( -24 hours) period. The respiratory rate increased during the postsurgical period and remained constant during the 72 hours of the critical period. During the assessment of the degree of pain in the postsurgical period, a statistically higher increase $(P=.01)$ was recorded at 24 hours postsurgery, which decreased to zero, indicating absence of pain, as the critical recovery period progressed (Table 2).

Presurgical and postsurgical clinical parameters obtained from horses with an enterotomy are grouped in Table 2. It was observed that as the postsurgical recovery period progressed, the levels of erythrocytes increased significantly $(P=.0001)$ compared with the presurgical period, with the highest values recorded at 72 hours postsurgery.

The leukocyte levels increased during the postsurgical period, with the highest levels recorded postsurgery at 24 and 48 hours. Neutrophil levels increased significantly $(P=.0001)$ during the first 24 hours of the postsurgical period compared to the presurgical period, and as the critical period progressed, values returned to normal. The highest lymphocyte levels were recorded in samples obtained at 48 and 72 hours postsurgery. The plasma protein levels were high throughout the critical period, and the values were statistically different from those recorded prior to the surgical procedure.

\subsection{Laparotomy With Enterectomy Technique: Presurgical and Postsurgical Evaluation}

There was a statistical increase $(P=.001)$ of heart rate at 24 hours postsurgery compared with the presurgical period, and as the recovery period progressed, it decreased back toward baseline levels. The respiratory rate increased significantly $(P=.03)$ at 72 hours postsurgery. The degree 
Table 1

Presurgical and postsurgical physical, echographic, and hemogram analysis of horses that underwent exploratory laparotomy (mean \pm SEM).

\begin{tabular}{|c|c|c|c|c|c|}
\hline \multirow[t]{2}{*}{ Variables } & \multirow{2}{*}{$\begin{array}{c}\text { Presurgical } \\
-24 \text { Hours }\end{array}$} & \multicolumn{4}{|l|}{ Postsurgical } \\
\hline & & 24 Hours & 48 Hours & 72 Hours & $P$-Value \\
\hline \multicolumn{6}{|l|}{ Physical and echographic } \\
\hline Heart rate (beats/min) & $32.85 \pm 0.56$ & $40.7 \pm 2.28^{\mathrm{a}}$ & $35.35 \pm 1.02$ & $35 \pm 2.06$ & .03 \\
\hline Respiratory frequency (breaths/min) & $8.4 \pm 0.12$ & $9.3 \pm 0.48$ & $9.65 \pm 0.63$ & $9.7 \pm 0.78$ & .36 \\
\hline Pain degree & 0 & $0.5 \pm 0.2^{\mathrm{a}}$ & $0.1 \pm 0.06$ & $0^{\mathrm{b}}$ & .01 \\
\hline Jejunal wall thickness $(\mathrm{mm})$ & $2.32 \pm 0.14$ & $2.78 \pm 0.23$ & $3.04 \pm 0.24$ & $2.96 \pm 0.16$ & .1 \\
\hline \multicolumn{6}{|l|}{ Clinical evaluation } \\
\hline Complete blood count (L/L) & $0.32 \pm 0.01$ & $0.33 \pm 0.01$ & $0.36 \pm 0.01$ & $0.35 \pm 0.02$ & .24 \\
\hline Hemoglobin $(\mathrm{g} / \mathrm{L})$ & $109.4 \pm 1.72$ & $117.4 \pm 3.5$ & $117.8 \pm 1.37$ & $115.4 \pm 9.6$ & .65 \\
\hline Erythrocytes $\left(\times 10^{12} / \mathrm{L}\right)$ & $7.02 \pm 0.4$ & $8.02 \pm 0.03^{\mathrm{a}}$ & $8.04 \pm 0.02^{a}$ & $7.94 \pm 0.05^{\mathrm{a}}$ & .006 \\
\hline Leucocytes $\left(\times 10^{9} / \mathrm{L}\right)$ & $9.8 \pm 0.42$ & $11.3 \pm 0.2^{\mathrm{a}}$ & $11.4 \pm 0.26^{a}$ & $9.8 \pm 0.1^{\mathrm{b}, \mathrm{c}}$ & .0004 \\
\hline Neutrophils $\left(\times 10^{9} / \mathrm{L}\right)$ & $3.24 \pm 0.22$ & $9.1 \pm 0.52^{\mathrm{a}}$ & $5.86 \pm 0.85^{\mathrm{b}}$ & $4.64 \pm 0.92^{\mathrm{b}}$ & .0001 \\
\hline Lymphocytes $\left(\times 10^{9} / \mathrm{L}\right)$ & $3.04 \pm 0.05$ & $2.36 \pm 0.11^{\mathrm{a}}$ & $3.12 \pm 0.06^{\mathrm{b}}$ & $3.1 \pm 0.08^{\mathrm{b}}$ & .0001 \\
\hline Proteins $(\mathrm{g} / \mathrm{L})$ & $69.2 \pm 1.34$ & $76.6 \pm 0.69^{\mathrm{a}}$ & $77.4 \pm 1.97^{\mathrm{a}}$ & $74.4 \pm 2.28$ & .01 \\
\hline
\end{tabular}

Abbreviation: SEM, standard error of the mean.

a Statistically different versus -24 hours.

b Different versus 24 hours.

c Different versus 48 hours.

of pain increased at 24 hours postsurgery and then gradually decreased; however, at 72 hours postsurgery, pain was still present. The jejunum wall thickness was greater $(P=.001)$ after the surgical procedure and remained so throughout the critical period (Table 3 ).

The clinical parameters of patients who underwent an enterectomy are summarized in Table 3. Hemoglobin levels increased significantly $(P=.0001)$ during the postoperative period, with the highest value recorded at 72 hours postsurgery. Erythrocyte values were higher in the postsurgical period and were statistically different $(P<.05)$ from the baseline values ( -24 hours). Regarding leukocytes and neutrophils, there were statistical increases in these compared to baseline values at 24-48 hours postsurgery. The highest levels of lymphocytes were reported in the presurgical period and at 72 hours in the postsurgical period. Plasma protein concentrations were higher throughout the critical period compared to the presurgical period.

\section{Discussion}

In the equine population in this study, an increased heart rate during the enterectomy technique with an average of 45 beats per minute was identified. Moore and Moore [16] reported that the heart rate is a very sensitive indicator of pain, hypovolemia, and endotoxic shock in horses. Proudman et al [3] reported a heart rate of $50 \pm 19$ beats/min between 15 and 25 hours after abdominal surgery in 341 horses aged $10 \pm 6.4$ years old. The highest heart rate value recorded was 45 beats/min in horses that underwent enterectomy at 72 hours postsurgery; in this sense, enterotomy represents a more invasive surgical procedure but with an optimal recovery prognosis. This may be because at 72 hours postsurgery, the equine heart rate returns to its basal values, reflecting absence of pain $[1,13,16]$. The identification of the heart rate is indispensable for the surgeon since this variable is associated with the patient's prognosis [17]. Heart rate analysis is a noninvasive technique that may

Table 2

Presurgical and postsurgical physical, echographic, and hemogram analysis of horses that underwent an enterotomy (mean \pm SEM).

\begin{tabular}{|c|c|c|c|c|c|}
\hline \multirow[t]{2}{*}{ Variables } & \multirow{2}{*}{$\frac{\text { Presurgical }}{-24 \text { Hours }}$} & \multicolumn{4}{|l|}{ Postsurgical } \\
\hline & & 24 Hours & 48 Hours & 72 Hours & $P$-Value \\
\hline \multicolumn{6}{|l|}{ Physical and echographic } \\
\hline Heart rate (beats/min) & $32.85 \pm 0.51$ & $41.1 \pm 2.2^{\mathrm{a}}$ & $34.2 \pm 1.3$ & $37.45 \pm 2.27$ & .01 \\
\hline Respiratory frequency (breaths/min) & $8.4 \pm 0.09$ & $10 \pm 0.42^{\mathrm{a}}$ & $10.5 \pm 0.34^{\mathrm{a}}$ & $10.6 \pm 0.53^{\mathrm{a}}$ & .003 \\
\hline Pain degree & 0 & $1.15 \pm 0.39^{\mathrm{a}}$ & $0.75 \pm 0.31$ & $0^{\mathrm{b}}$ & .01 \\
\hline Jejunal wall thickness (mm) & $2.5 \pm 0.17$ & $3.2 \pm 0.23$ & $2.98 \pm 0.16$ & $3.52 \pm 0.31$ & .07 \\
\hline \multicolumn{6}{|l|}{ Clinical evaluation } \\
\hline Complete blood count (L/L) & $0.32 \pm 0.01$ & $0.36 \pm .009$ & $0.34 \pm 0.01$ & $0.35 \pm 0.01$ & .25 \\
\hline Hemoglobin $(\mathrm{g} / \mathrm{L})$ & $108 \pm 5.01$ & $113.6 \pm 4.18$ & $115.6 \pm 4.13$ & $118.8 \pm 7.5$ & .54 \\
\hline Erythrocytes $\left(\times 10^{12} / \mathrm{L}\right)$ & $6.9 \pm 0.06$ & $7.8 \pm 0.04^{\mathrm{a}}$ & $7.8 \pm 0.03^{\mathrm{a}}$ & $8.24 \pm 0.02^{\mathrm{a}, \mathrm{b}, \mathrm{c}}$ & .0001 \\
\hline Leucocytes $\left(\times 10^{9} / \mathrm{L}\right)$ & $9.9 \pm 0.11$ & $11.9 \pm 0.37^{\mathrm{a}}$ & $11.8 \pm 0.27^{\mathrm{a}}$ & $11.0 \pm 0.58$ & .005 \\
\hline Neutrophils $\left(\times 10^{9} / \mathrm{L}\right)$ & $3.36 \pm 0.06$ & $9.5 \pm 1.1^{\mathrm{a}}$ & $6.9 \pm 0.27^{\mathrm{a}}$ & $5.3 \pm 0.72^{\mathrm{b}}$ & .0001 \\
\hline Lymphocytes $\left(\times 10^{9} / \mathrm{L}\right)$ & $3.08 \pm 0.1$ & $2.62 \pm 0.21$ & $3.38 \pm 0.08^{\mathrm{b}}$ & $3.18 \pm 0.1^{\mathrm{b}}$ & .007 \\
\hline Proteins $(g / L)$ & $67.8 \pm 1.37$ & $82.8 \pm 1.85^{\mathrm{a}}$ & $77.4 \pm 1.97^{\mathrm{a}}$ & $77.6 \pm 0.94^{\mathrm{a}}$ & .0001 \\
\hline
\end{tabular}

Abbreviation: SEM, standard error of the mean.

a Statistically different versus -24 hours.

b Different versus 24 hours.

c Different versus 48 hours. 
Table 3

Presurgical and postsurgical physical, echographic, and hemogram analysis of horses that underwent an enterectomy (mean \pm SEM).

\begin{tabular}{|c|c|c|c|c|c|}
\hline \multirow[t]{2}{*}{ Variables } & \multirow{2}{*}{$\frac{\text { Presurgical }}{-24 \text { Hours }}$} & \multicolumn{4}{|l|}{ Postsurgical } \\
\hline & & 24 Hours & 48 Hours & 72 Hours & $P$-Value \\
\hline \multicolumn{6}{|l|}{ Physical and echographic } \\
\hline Heart rate (beats/min) & $32.95 \pm 0.47$ & $49.4 \pm 2.57^{\mathrm{a}}$ & $43.8 \pm 3.11^{\mathrm{a}}$ & $41.8 \pm 2.57$ & .001 \\
\hline Respiratory frequency (breaths/min) & $8.6 \pm 0.12$ & $10 \pm 0.63$ & $10.55 \pm 0.74$ & $10.65 \pm 0.2^{\mathrm{a}}$ & .03 \\
\hline Pain degree & 0 & $1 \pm 0.17^{\mathrm{a}}$ & $0.6 \pm 0.2$ & $0.55 \pm 0.24$ & .04 \\
\hline Jejunal wall thickness (mm) & $2.38 \pm 0.17$ & $3.76 \pm 0.27^{\mathrm{a}}$ & $3.74 \pm 0.16^{\mathrm{a}}$ & $3.38 \pm 0.24^{a}$ & .001 \\
\hline \multicolumn{6}{|l|}{ Clinical evaluation } \\
\hline Complete blood count (L/L) & $0.31 \pm 0.01$ & $0.36 \pm 0.005$ & $0.34 \pm 0.007$ & $0.35 \pm 0.02$ & .109 \\
\hline Hemoglobin $(\mathrm{g} / \mathrm{L})$ & $109 \pm 1.6$ & $121 \pm 1.6^{\mathrm{a}}$ & $123.4 \pm 0.24^{\mathrm{a}}$ & $130.8 \pm 3.13^{a, b}$ & .0001 \\
\hline Erythrocytes $\left(\times 10^{12} / \mathrm{L}\right)$ & $7.44 \pm 0.28$ & $8.42 \pm 0.05^{\mathrm{a}}$ & $8.52 \pm 0.03^{a}$ & $8.7 \pm 0.04^{a}$ & .0001 \\
\hline Leucocytes $\left(\times 10^{9} / \mathrm{L}\right)$ & $9.92 \pm 0.29$ & $13.5 \pm 0.26^{a}$ & $13.2 \pm 0.1^{\mathrm{a}}$ & $12.1 \pm 0.3^{\mathrm{a}, \mathrm{b}, \mathrm{c}}$ & .0001 \\
\hline Neutrophils $\left(\times 10^{9} / \mathrm{L}\right)$ & $3.25 \pm 0.05$ & $13.3 \pm 0.38^{a}$ & $12.1 \pm 0.23^{\mathrm{a}, \mathrm{b}}$ & $7.06 \pm 0.2^{\mathrm{a}, \mathrm{b}, \mathrm{c}}$ & .0001 \\
\hline Lymphocytes $\left(\times 10^{9} / \mathrm{L}\right)$ & $3.04 \pm 0.05$ & $2.7 \pm 0.04^{\mathrm{a}}$ & $2.84 \pm 0.02$ & $3.16 \pm 0.12^{b, c}$ & .001 \\
\hline Proteins $(\mathrm{g} / \mathrm{L})$ & $68 \pm 1.7$ & $84 \pm 1.43^{\mathrm{a}}$ & $85.2 \pm 0.38^{a}$ & $79.2 \pm 2.51^{\mathrm{a}}$ & .0001 \\
\hline
\end{tabular}

Abbreviation: SEM, standard error of the mean.

a Statistically different versus -24 hours.

b Different versus 24 hours.

c Different versus 48 hours.

provide diagnostic and prognostic information pertinent to the management of postoperative horse with gastrointestinal disease requiring exploratory laparotomy [18]. Moore and Moore [16] and Proudman et al [19] showed that persistent heart rates above 80 beats per minute are generally associated with a poor prognosis.

Recognizing the degree of pain in horses allows for optimization of animal welfare, and this has received significant interest in recent decades [6]. The degree of pain in horses subjected to the enterectomy technique was the highest according to the level of pain. It was categorized as 1.5 with behavioral signs of mild-to-moderate colic but not more than grade two established in the prognosis in Equine Medical and Surgical Colic [18]; Mair [10] indicated that the more severe the disease, the more intense the pain.

Abdominal ultrasound allows the thickness of the intestinal wall to be measured. Kalck [20] noted that when there is moderate distension, thickness is $3 \mathrm{~mm}$ or less. In this study, jejunum wall thickness was measured during the presurgical and postsurgical periods, and it was higher after surgical manipulation in animals included in the enterectomy technique. One possible explanation is that when an injury occurs, there is local vasodilation of blood vessels with consequent excessive blood flow and increased capillary permeability, which allows fluid leakage into the interstitium and coagulation of the interstitial fluid due to increased fibrinogen and proteins exiting capillaries [21]. In humans and mice, intestinal manipulation results in an inflammatory reaction with subsequent decreased intestinal motility after surgery [22,23]. Several studies [8,24] agree that mechanical intestinal manipulation causes a rapid local inflammatory reaction in the mucosa, submucosa, and serosa including an eosinophilic mucous response.

Freeman et al [25] reported that there was no effect on heart rate and the present pathology. This is contrary to the findings of Reeves et al [26], who found that a number of variables related to vascular compromise (hematocrit, heart rate, capillary refill time, pulse quality) were associated with the survival of the horse with acute abdomen. Similarly, in the present study, a statistically higher elevation in heart rate was obtained within the first 24 hours of the critical patient recovery period regardless of the laparotomy technique used. The comparison of different surgical techniques performed in this study showed that enterectomy was the procedure with the most adverse effects on the first postsurgical day. Muñoz et al [27] working with different types of surgical intervention grouped into seven categories showed that of the 468 cases of exploratory laparotomies, only 50 had enterectomy surgery and horses that underwent an enterectomy were significantly more affected by postoperative ileus $(P=.025)$, colic $(P<.005)$, peritonitis $(P=.025)$, laminitis $(P=.078)$, and endotoxemia $(P=.084)$ and had lower surgical survival rate and complications. This is consistent with other studies where it was reported that horses undergoing an enterectomy were prone to shortterm complications like inflammation, pain, ileus, and endotoxic shock $[28,29]$. A potential reason why the enterectomy may have short-term complications is that horses requiring this technique may have more severe pathologies of the small intestine [25].

\section{Conclusions}

The laparotomy surgical techniques is one of the most common procedures performed on horses hospitalized due to signology of acute abdominal syndrome. The manipulation of the jejunal during the enterectomy technique increased heart rate and pain level in the first 24 hours which returned to normal at 72 hours postoperatively. The comparison of the different surgical techniques performed in this study shows that the enterectomy technique is the procedure with the greatest adverse effects in the first 72 hours postoperatively.

\section{References}

[1] Ihler FC, Larsen Venger J, Skjerve E. Evaluation of clinical and laboratory variables as prognostic indicators in hospitalised gastrointestinal colic horses. Acta Vet Scand 2004;45:109-18. 
[2] Valladares-Carranza B, Zamora-Espinosa JL, Velázquez-Ordóñez V, Gutiérrez-Castillo A, Ortega-Santana C, Pérez-Sotelo LS. Síndrome abdominal agudo en una potranca. Estudio de caso. REDVET. Rev Electron Vet 2012;8:1-9.

[3] Proudman CJ, Smith JE, Edwards GB, French NP. Long-term survival of equine surgical colic cases. Part 2: modelling postoperative survival. Equine Vet J 2002;34:438-43.

[4] Adams SB. Principios de cirugía abdominal. In: Colahan P, Mayhew I, Merrit A, Moore J, editors. Medicina y cirugía equina. 3th ed. Buenos Aires: Intermédica; 1998. p. 469-85.

[5] Krueger CR, Klohnen A. Surgical correction of nephrosplenic entrapment of the large colon in 3 horses via standing left flank laparotomy. Vet Surg 2015;11:392-7.

[6] Dujardin CLL, Van Loon JPAM. Pain recognition and treatment in the horse: a survey of equine veterinarians in The Netherlands and Belgium. Tijdschr Diergeneesk 2011;136:715-24.

[7] Ducharme NG. Abordajes quirúrgicos abdominales. In: Mair T, Divers T, Ducharme N, editors. Manual de gastroenterología equina. 1st ed. Buenos Aires, Argentina: Intermédica; 2003. p. 183-7.

[8] Hopster-Iversen C, Hopster K, Staszyk C, Rohn K, Freeman D, Rotting AK. Influence of mechanical manipulations on the local inflammatory reaction in the equine colon. Equine Vet J 2011;43:1-7.

[9] NOM-024-ZOO-1995. Norma Oficial Mexicana, Especificaciones y características zoosanitarias para el transporte de animales, sus productos y subproductos, productos químicos, farmacéuticos, biológicos y alimenticios para uso en animales o consumo por éstos. Diario Oficial de la Federación 1995.

[10] Mair T. Evaluación clínica del paciente con cólico. In: Mair T, Divers T, Ducharme N, editors. Manual de gastroenterología equina. 1st ed. Buenos Aires: Intermédica; 2003. p. 127-70.

[11] Busoni V, De Busscher V, Lopez D, Verwilghen D, Cassart D. Evaluation of a protocol for fast localised abdominal sonography of horses (FLASH) admitted for colic. Vet J 2011;188:77-82.

[12] Beccati F, Pepe M, Gialletti R, Cercone M, Bazzica C, Nannarone S. Is there a statistical correlation between ultrasonographic findings and definitive diagnosis in horses with acute abdominal pain? Equine Vet J 2011;43:98-105.

[13] Sánchez LC, Robertson SA. Pain control in horses: what do we really know? Equine Vet J 2014;46:517-23.

[14] Dallap-Schaer BL, Linton JK, Aceto H. Antimicrobial use in horses undergoing colic surgery. J Vet Intern Med 2012;26:1449-56.

[15] Rooney DK. Clinical nutrition. In: Reed S, Bayly WM, editors. Equine Internal Medicina. 2nd ed. Philadelphia: WB Saunders; 1998. p. 216-50.
[16] Moore BR, Moore RM. Examination of the equine patient with gastrointestinal emergency. Vet Clin North Am Equine Pract 1994; 10:549-66.

[17] van der Linden MA, Laffont CM, van OldruitenborghOosterbaan MMS. Prognosis in equine medical and surgical colic. J Vet Intern Med 2003;17:343-8.

[18] McConachie EL, Giguère S, Rapoport G, Barton MH. Heart rate variability in horses with acute gastrointestinal disease requiring exploratory laparotomy. J Vet Emerg Crit Care 2016;2:269-80.

[19] Proudman CJ, Edwards GB, Barnes J, French NP. Modelling longterm survival of horses following surgery for large intestinal disease. Equine Vet J 2005;37:366-70.

[20] Kalck KA. Inflammatory bowel disease in horses. Vet Clin Equine 2009;25:303-15.

[21] Guyton AC, Hall JE. Fisiología gastrointestinal. In: Tratado de Fisiología Médica. 10th ed. México: Mc GrawHill; 2011. p. 799-804.

[22] Kalff JC, Türler A, Schwarz NT, Schraut WH, Lee KKW, Tweardy DJ. Intra-Abdominal activation of a local inflammatory response within the human muscularis externa during laparotomy. Ann Surg 2003; 237:301-15.

[23] Schwarz NT, Kalff JC, Türler A, Speidel N, Grandis JR, Billaiar TR. Selective jejunal manipulation causes postoperative pan-enteric inflammation and dysmotility. Gastroenterology 2004;126: 159-69.

[24] Rötting AK, Freeman DE, Constable PD, Eurell JA, Wallig M. Mucosal distribution of eosinophilic granulocytes within the gastrointestinal tract of horses. Am J Vet Res 2008;69:874-9.

[25] Freeman DE, Hammock P, Baker GJ, Foreman JH, Schaeffer DJ Richter RA. Short- and Long-term survival and prevalence of post operative ileus after small intestinal surgery in the horse. Equine Vet J 2000;32:42-51.

[26] Reeves MJ, Curtis CR, Salman MD, Stashak TS, Reif JS. Validation of logistic regression models used in the assessment of prognosis and the need for surgery in equine colic patients. Prev Vet Med 1992;13: 155-72.

[27] Muñoz E, Argüelles D, Areste L, San Miguel L, Prades M. Retrospective analysis of exploratory laparotomies in 192 Andalusian horses and 276 horses of other breeds. Vet Rec 2008;162:303-6.

[28] Mair TS, Smith LJ. Survival and complication rates in 300 horses undergoing surgical treatment of colic. Part 1: short-term survival following a single laparotomy. Equine Vet J 2005;37:269-302.

[29] Mair TS, Smith LJ. Survival and complication rates in 300 horses undergoing surgical treatment of colic. Part 2: short-term complications. Equine Vet J 2005;37:303-9. 